\title{
Interferon $\gamma$ induced compositional changes in human bone marrow derived mesenchymal stem/stromal cells
}

\author{
Qingdong Guan ${ }^{1,2}$, Peyman Ezzati ${ }^{3}$, Victor Spicer ${ }^{3}$, Oleg Krokhin³ ${ }^{3}$ Donna Wall ${ }^{4}$ and John A. Wilkins ${ }^{3 *}$
}

\begin{abstract}
Background: Mesenchymal stem/stromal cells (MSC) display a range of immunoregulatory properties which can be enhanced by the exposure to cytokines such interferon $\gamma$ (IFN- - ). However the compositional changes associated with the 'licensing' of these cells have not been clearly defined. The present study was undertaken to provide a detailed comparative proteomic analysis of the compositional changes that occur in human bone marrow derived MSC following $20 \mathrm{~h}$ treatment with IFN- $\gamma$.
\end{abstract}

Methods: 2D LC MSMS analysis of control and IFN- $\gamma$ treated cells from 5 different healthy donors provided confident identification of more than 8400 proteins.

Results: In total 210 proteins were shown to be significantly altered in their expression levels $(\geq|2 S D|)$ following IFN- $\gamma$ treatment. The changes for several of these proteins were confirmed by flow cytometry. STRING analysis determined that approximately $30 \%$ of the altered proteins physically interacted in described interferon mediated processes. Comparison of the list of proteins that were identified as changed in the proteomic analysis with data for the same proteins in the Interferome DB indicated that $\sim 35 \%$ of these proteins have not been reported to be IFN- $\gamma$ responsive in a range of cell types.

Conclusions: This data provides an in depth analysis of the proteome of basal and IFN- $\gamma$ treated human mesenchymal stem cells and it identifies a number of novel proteins that may contribute to the immunoregulatory capacity if IFN- $\gamma$ licensed cells.

Keywords: Proteomics, Human, 2D LC mass spectrometry, Interferon $\gamma$, Mesenchymal stem/stromal cells (MSC), Quantitative proteome profiling, Licensing, Membrane

\section{Background}

Mesenchymal stem/stromal cells (MSC) are multipotent stromal cells derived from all mammalian supportive stromal tissue compartments containing distinct pools of endogenous progenitor cells. MSC possess the potential for self-renewal and multi-lineage differentiation. The demonstration that MSC can also display potent

\footnotetext{
*Correspondence: John.Wilkins@umanitoba.ca

${ }^{3}$ Manitoba Centre for Proteomics and Systems Biology, Section

of Biomedical Proteomics, Department of Internal Medicine, Rady Faculty of Health Sciences, University of Manitoba and Health Sciences Centre, 799 John Buhler Research Centre, 715 McDermot Ave, Winnipeg, MB R3E 3P4, Canada

Full list of author information is available at the end of the article
}

immunoregulatory activities has led to marked interest in their potential use in the treatment of autoimmunity and transplant rejection [1-4]. The underlying processes include both contact dependent (e.g. PDL-1) and soluble effector mediated processes (e.g. IDO-1) [5, 6]. Additionally, MSC can regulate innate and adaptive immune responses through the release of soluble mediators (e.g. IL-10, TGF $\beta$ ), the induction of regulatory $\mathrm{T}$ cells (Treg) and the suppression effector $\mathrm{CD} 4+$ and $\mathrm{CD} 8+\mathrm{T}$ cells [7-11]. The fact that this activity may be enhanced by treatment of MSC with cytokines such as TNF $\alpha$, IFN- $\gamma$, IL-17, IL-1 $\alpha$ or IL-1 $\beta$, has resulted in several protocols for possible 'licensing' of MSC [12-15]. Although a number of pathways have been implicated in this process, the 
underlying mechanisms responsible for the immunoregulatory activity have not been fully elucidated. These observations highlight the need for an understanding of the responses of MSC to treatment with the cytokines.

To date there have been a limited number of detailed analysis of the proteomes of MSC. In many of these studies, the focus has been largely on the comparative analysis of cells from different tissue sources, and/or multi-tissue differentiation ability, tissue repair and self-renewal $[16,17]$ or more recently relating to the secretomes of various cells [18-20]. Significantly the majority of these studies have used fetal bovine serum (FBS) expanded MSC for proteomics analysis which will not be used in the manufacturing of clinical grade MSC. In fact there have been very few studies that have examined MSC and their responses to cytokine stimulation. Thus the basis for cytokine enhanced MSC immunoregulatory activity is not fully understood.

The aim of the present study was to determine the changes in protein composition that occur in GMP grade human platelet lysate expanded MSC subsequent to $20 \mathrm{~h}$ of treatment with interferon $\gamma$. The focus was specifically on those proteins that displayed consistent and significant alterations in their expression patterns following treatment. These proteins might ultimately be useful in identifying markers to assess the IFN- $\gamma$ responses of treated cells or in defining the compositional changes mechanistically involved in the immunoregulatory features of the licensed cells.

\section{Methods}

\section{Chemicals}

All chemicals were sourced from Sigma Chemicals (St-Louis, MO), unless noted otherwise. HPLC-grade acetonitrile and de-ionized water were used for the preparation of eluents. Sequencing-grade modified trypsin (Promega, Madison, WI) and $15 \mathrm{~mL}$ Amicon centrifugal filter units (Merck Millipore, Ireland) was used for digestion. Siliconized $1.5 \mathrm{~mL}$ vials (BioPlas, San Rafael, CA) were used for all sample preparation and fractions handling steps.

\section{MSC expansion and licensing}

Bone marrow aspirates were obtained from the posterior iliac crest of normal volunteers under institutional REB-approved study. The donors were 4 males and 1 female ranging in age from 8 to 41 years. Bone marrowderived MSC cultures were established and maintained in a GMP compliant facility as described previously [21]. To license MSC, cells from the first or second passage were seeded into T175 flasks at $2000-3000$ cells $/ \mathrm{cm}^{2}$ in complete DMEM media (Lonza, USA) with 5\% human platelet lysate (Mill Creek Life Sciences, Rochester, USA), 1\% glutamax (Life technologies, California, USA) and gentamicin (5 $\mu \mathrm{g} / \mathrm{ml}$, Life Technologies); When the cell confluence reached $70-80 \%$, human recombinant IFN- $\gamma$ (eBioscience, California, USA) was added into the MSC culture media at $30 \mathrm{ng} / \mathrm{mL}$ for $20 \mathrm{~h}$ and then cells were released with tryple select (Life Technologies), washed with DPBS and analyzed [22].

\section{Phenotyping of MSC}

The immunophenotype of expanded MSCs was characterized by flow cytometry as described previously (Minimal criteria for defining multipotent mesenchymal stromal cells [23]. Briefly, $0.5 \times 10^{6}$ MSCs were washed in FACS buffer, and then incubated with Fc block for 10 min. This was followed by staining with FITC, APC or PE -labelled antibodies against surface molecules CD90, CD73, CD105, CD34, CD45, CD14, HLA-DR, CD19 and isotype control (eBioscience) respectively, for $20 \mathrm{~min}$ according to the manufacturer recommendations. After staining, cells were acquired and analyzed using flow cytometry (FACS Canto II, BD Biosciences, San Jose, USA) and FlowJo software (TreeStar, San Carlos, CA, USA).

Using the same methods, PE-Cy7, FITC, APC-Cy7 or Percp-Cy5.5 labeled antibodies against PD-L1, BST2, ICAM-1 and VCAM-1 (eBioscience), were used to evaluate the expression of PD-L1, BST-2, ICAM-1 and VCAM- 1 on the surface of MSC. To evaluate the expression of intracellular proteins IDO-1, MSC were fixed and permeabilized using eBioscience intracellular fixation/ permeabilization buffer. Cells were then stained with PE-labeled anti-IDO-1 for $20 \mathrm{~min}$. After staining, cells were acquired and analyzed using flow cytometry (FACS Canto II, BD Biosciences, San Jose, USA) and FlowJo software (TreeStar, San Carlos, CA, USA).

\section{MSC trilineage differentiation assay}

MSC were induced to differentiate into adipogenic, osteogenic or chondrogenic lineages, with the use of the STEMPRO Adipogenesis, Osteogenesis, and Chondrogenesis Differentiation Kit (Thermo Fisher Scientific) as described previously [24]. Briefly, MSC were seeded into 6-well plates at $3000 / \mathrm{cm}^{2}$ in DMEM with $5 \%$ human platelet lysate. When MSC were reached $80 \%$ confluency, each well was replaced with adipogenic, osteogenic or chondrogenic differentiation media according to the manufacturer's instruction for 14-21 days. The staining analysis was performed with the use of oil red $\mathrm{O}$, Alizarin red $\mathrm{S}$ and Safranin $\mathrm{O}$ staining for adipocytes, osteocytes and chondrocytes, respectively.

\section{Processing of cells for MS analysis}

Tryptic digests of MSC were prepared using the scaled up (15 ml filter units) FASP digestion procedure [25]. 
Protein amounts to be subjected to digestion were monitored using micro-BCA assay (Pierce, Rockford, IL). Resulting digest was acidified with TFA and purified by RP SPE. Approximately $100 \mu \mathrm{g}$ of the digests (determined by NanoDrop 2000, ThermoFisher) was used for 2D LCMS experiments [26].

\section{First dimension separation and fraction collection}

Agilent 1100 series LC system with UV detector $(214 \mathrm{~nm})$ and $3 \mathrm{~mm} \times 100 \mathrm{~mm}$ XTerra MS C18, $3.5 \mu \mathrm{m}$ column (Waters, Ireland) was used for $\mathrm{pH} 10$ separations. 0.66\% acetonitrile gradient (0-40\% acetonitrile) was delivered at $300 \mu \mathrm{L} / \mathrm{min}$ flow rate. Both eluents $\mathrm{A}$ (water) and B (1:9 water:acetonitrile) contained $20 \mathrm{mM}$ ammonium formate and were prepared by 1:10 dilution of $200 \mathrm{mM}$ ammonium solution with $\mathrm{pH} 10$ adjusted by formic acid. Manual Reodyne injector (Bensheim, Germany) with $200 \mu \mathrm{L}$ loop was used to deliver $\sim 100 \mu \mathrm{g}$ of digested sample onto the column. One-minute fractions were collected over the 7-55 min interval, concatenated into 21 fractions, lyophilized and re-suspended in buffer A $(0.1 \%$ formic acid in water).

\section{HPLC-MS settings in the second dimension}

A splitless nano-flow 2D LC Ultra system (Eksigent, Dublin, CA) was used to deliver water/acetonitrile gradient at $500 \mathrm{~nL} / \mathrm{min}$ flow rate through a $100 \mu \mathrm{m} \times 200 \mathrm{~mm}$ analytical column packed with $3 \mu \mathrm{m}$ Luna C18(2) (Phenomenex, Torrance, CA) at room temperature. Sample injection $(\sim 1 \mu \mathrm{g}$ of peptides from each fraction in $10 \mu \mathrm{L}$ of buffer A) via a $300 \mu \mathrm{m} \times 5 \mathrm{~mm}$ PepMap100 trap-column (ThermoFisher) was used in all experiments. The gradient program included following steps: linear increase from 0.5 to $30 \%$ of buffer B (acetonitrile) in $78 \mathrm{~min}, 5 \mathrm{~min}$ columns wash with $90 \% \mathrm{~B}$ and 8 min system equilibration using starting conditions of $0.5 \% \mathrm{~B}$. Both eluents $\mathrm{A}$ (water) and B (acetonitrile) contained $0.1 \%$ formic acid as ion-pairing modifier.

Data-dependent acquisition TripleTOF5600 mass spectrometer (Sciex, Concord, ON) was performed using following settings: $250 \mathrm{~ms}$ survey MS spectra (m/z 3001500 ) was followed by up to $20 \mathrm{MS} / \mathrm{MS}$ measurements on the most intense parent ions (300 counts/s threshold, +2 to +4 charge state, $\mathrm{m} / \mathrm{z} 100-1500$ mass range for MS/ MS, 100 ms each, high sensitivity mode). Previously targeted parent ions were excluded from repetitive MS/MS acquisition for $12 \mathrm{~s}$ (50 $\mathrm{mDa}$ mass tolerance).

\section{Data treatment and protein/peptide identification}

Raw spectra files were converted into Mascot Generic File format (MGF) for peptide/protein identification by $\mathrm{X}$ !Tandem search algorithm [27]. Ten combined MGF files (each containing 21 MGFs of individual fractions) were created for subsequent protein identification and quantitation. The following X!Tandem search parameters were used: 20 and $50 \mathrm{ppm}$ mass tolerance for parent and fragment ions, respectively; constant modification of Cys with iodoacetamide; default set post-translational modifications: oxidation of Met, Trp; N-terminal cyclization at Qln, Cys; N-terminal acetylation, phosphorylation (Ser, Thr, Tyr), deamidation (Asn and Gln); an expectation value cut-off of $\log (\mathrm{e})<-1$ for both proteins and peptides.

Spectra (in MGF format) and protein quantitation results are available at the University of California, San Diego's MassIVE archive (massive.ucsd.edu) under the accession MSV000080890.

\section{Results}

\section{Characterization of isolated MSC}

The isolated MSC were initially characterised to demonstrate that they expressed the appropriate surface markers and differentiation capacity as outlined by the International Society for Cell Therapy [23]. The cells expressed the MSC markers, CD90 (Thy-1), CD105 (endoglin) and CD 73 (ecto 5'nucleotidase). The cells lacked the pan-leukocyte marker CD45, the primitive hematopoietic and endothelial marker CD34, the B cell marker, CD19 and the macrophage/monocyte marker, CD14 as well as HLA-DR which is not expressed on MSC unless they have been activated (Fig. 1a). The capacity of the MSC to differentiate into chondrocytes, osteoblasts or adipocytes was also confirmed (Fig. 1b). Collectively these results indicate that the MSC isolates conformed to criteria for this designation.

\section{Protein identification and relative quantitation}

Paired digests of cell lysates of untreated and IFN- $\gamma$ treated MSC expanded from 5 separate healthy individuals were separated by $2 \mathrm{D}$ liquid chromatography and analysed by mass spectrometry. The resulting MGF spectra files for each analysis were sequentially concatenated and searched against a human subset of the Uniprot protein database (June 2015) using X!tandem (cyclone 2012.10.01.1). Confident protein identifications were selected based on the requirement for at least two distinct unique peptides each with expectation scores of -1.5 or lower and of -3 or lower for the protein. Peptide and protein identification statistics are summarized (Additional file 1: Table S1) which illustrate the significant and uniform depth of coverage across the five donor paired samples. A total of 8437 proteins were identified with 4500 shared proteins being observed in all of the analyses.

Label-free protein expression values were computed as the sum of MS/MS fragment intensities for identified 

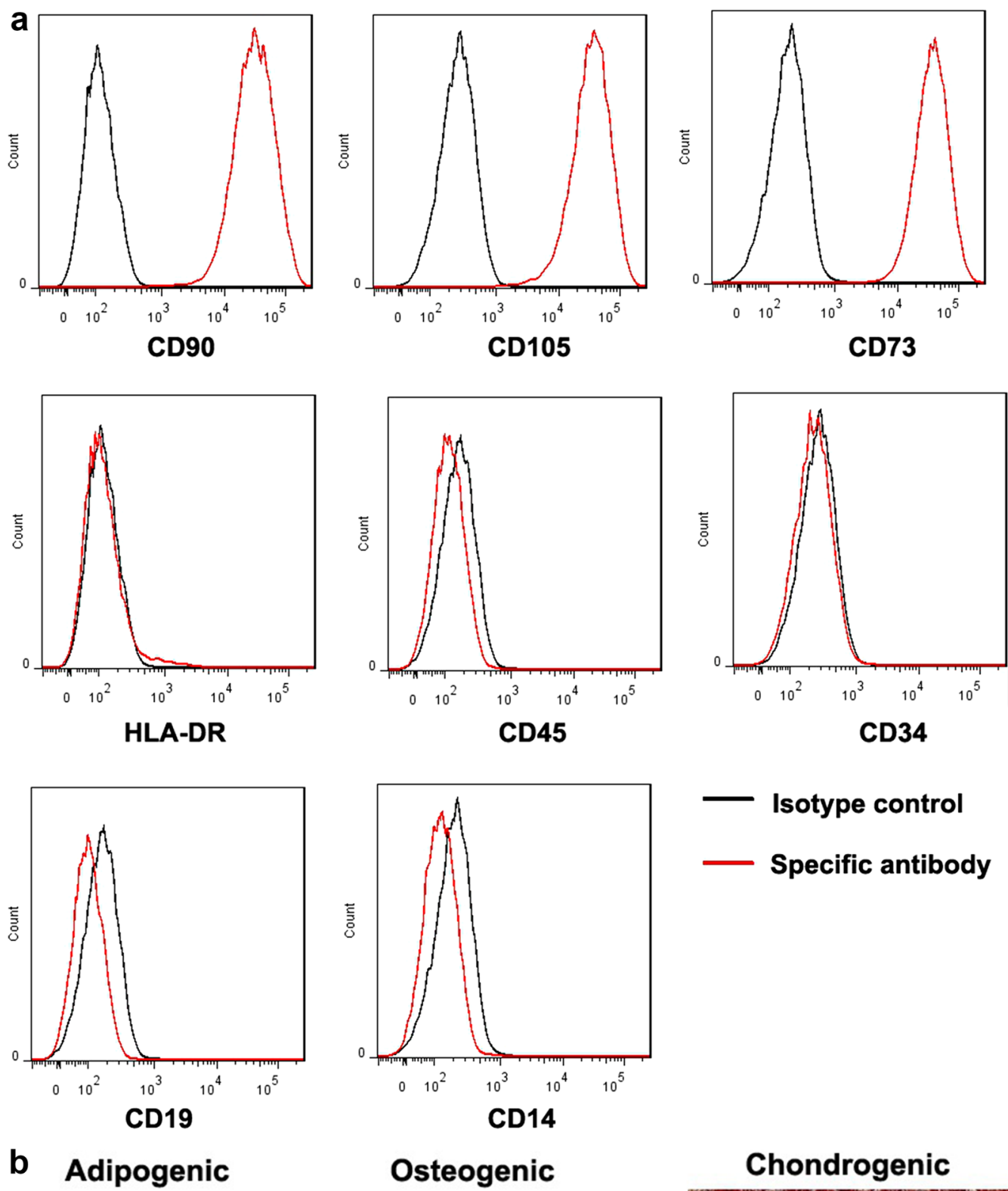

\section{Osteogenic}
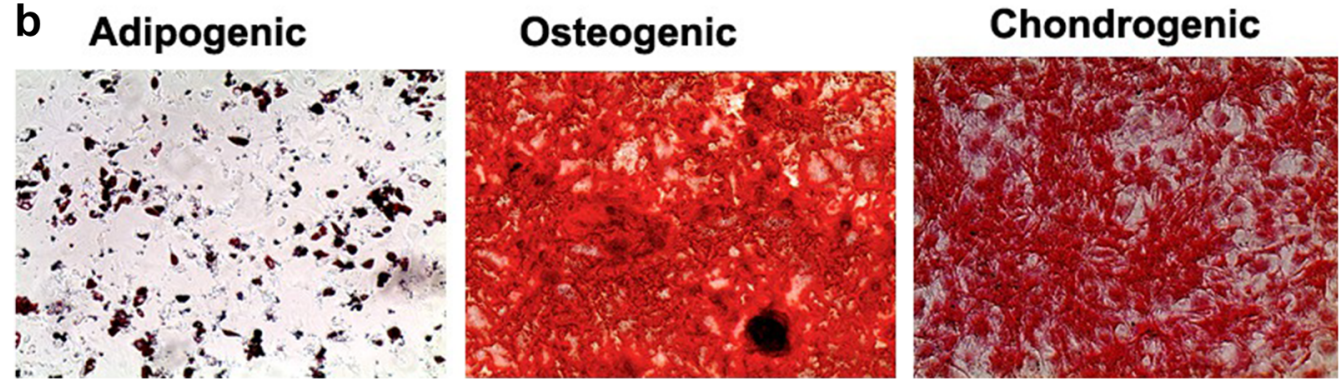

Fig. 1 Characterization of MSC: representative data is provided for a flow cytometric analysis indicating that the cells displayed MSC markers CD90, CD105 and CD73 and the absence of lymphoid and myeloid cell markers and $\mathbf{b}$ differentiation capacity of MSC. Cells were assessed for their capacity to undergo Adipogenic (Oil Red O staining of lipid droplets after 14 days of induction); Osteogenic (Alizarin Red staining of calcium phosphate deposits produced by osteocytes after 21 days of induction; Chodrogenic (Safranin O staining of collagen matrix forming chondrocytes after 14 days of induction). (Original magnification $\times 100$ ). All MSC met the International Society for Cell Therapy criteria for MSC 
member peptides for each of the ten MS runs. In order to be included for quantification, at least two non-redundant peptide sequences were required for each protein. Protein level expression sums were mapped into a $\log _{2}$ scale and protein-by-protein differential analysis [D $=($ IFN intensity) - (CONTROL intensity)] was calculated across each of the donor cell pairs. These five donor protein-level differences each manifested as three Gaussian populations, with proteins observed in both modes forming the central population, and proteins observed uniquely in one mode or the other forming the other two populations. Selection of proteins for relative quantitation was based on a requirement that at least two non-redundant peptides were detected in the observed mode. Each central difference population was used for the normalization (mean $=0, S D=1)$ of all three difference populations; while the resulting outer two difference population's Z-scores were not directly informative of the probability of the difference being a random event. However, putting all measurements into a common scale made the comparative analysis across the five donors possible (Additional file 1: Table S1).

The data was analysed to identify those proteins in the IFN- $\gamma$ treated population that showed a change of greater than two standard deviations from the mean of the overall protein change in the population (i.e. the mean difference of $[D=$ (IFN intensity) - (CTL intensity)]. This corresponded to a $\sim 3$ fold difference in signal intensity because all five cell pairs had approximately the same difference distribution standard deviations. The criteria for assigning a protein differentially expressed status was based on a requirement that the protein displayed a consistent significant change in at least 3 of the 5 cell pairs following interferon treatment. This approach resulted in the identification of 169 proteins with increased expression and 41 proteins with decreased levels following interferon treatment (Tables 1A, B, 2A, B).

\section{Flow cytometric analysis of IFN- $\gamma$ treated MSC}

In an independent series of experiments the levels of expression of selected candidates (i.e. VCAM-1, ICAM1, IDO1, PDL1 and BST2) were compared between IFN- $\gamma$ treated and the corresponding untreated MSC populations (Fig. 2). These proteins were all predicted from the proteomic analysis to increase following IFN- $\gamma$ treatment. The flow cytometry results indicated that IDO1 and BST2 levels increased from being virtually undetectable to being highly expressed on all cells following treatment. The expression levels of PDL1, ICAM1 and VCAM1 increased from very low but to detectable levels to markedly increased expression in the IFN- $\gamma$ treated group. These results were consistent with those of the mass spectrometry analysis and offered an independent validation of the proteomic expression results.

\section{Network and GO analysis}

The list of significantly changed proteins identified in the proteomic analysis was submitted for STRING network analysis [28]. The analysis settings were: confidence level of 0.7 or greater using only evidence derived from databases and experiments. Analysis of the entire list indicated a highly organised and significant network $(p=0)$ with an average degree of 2.81 and a clustering coefficient of 9.45. There was a single dominant network consisting of 51 proteins which displayed a high level of connectivity. The remainder of the interacting proteins $(n=21)$ were associated with 7 smaller groups consisting of 2 or 3 interactors (Fig. 2). Thus of the 169 proteins that were increased following IFN- $\gamma$ treatment $\sim 40 \%(n=68)$ were components of a protein-protein interaction network as determined by STRING. A separate analysis of the proteins that were decreased following IFN $-\gamma$ treatment indicated that there were no significant protein-protein interactions in this group.

Functional analysis of the altered proteins using GO indicated that there was a highly significant enrichment of proteins $(n=73)$ related to host defence responses $\left(\mathrm{FDR} 4.97 \times 10^{-33}\right)$. The proteins were enriched for "Interferon gamma-mediated signalling pathway" $\left(\mathrm{n}=19\right.$, FDR $\left.9.31 \times 10^{-21}\right)$. There was also a significant enrichment in proteins that were designated as involved in "Type I interferon signalling pathway" $\left(\mathrm{n}=23\right.$, FDR $\left.6.78 \times 10^{-27}\right)$. Although many of the upregulated proteins identified were common to both of the interferon signalling pathways, there were some clear differences in the proteins associated with the two pathways (Fig. 3). The remaining interacting proteins were components of shared pathways or processes (e.g. PTGES/PTGS2/PTGIS, APOBEC3F/ APOBEC3G).

\section{Relationship between IFN- $\gamma$ induced proteomic and transcriptomic changes}

The protein lists were also submitted to the Interferome DB to determine if there was any evidence of corresponding altered gene expression levels in response to IFN- $\gamma$ treatment [29]. To be consistent with our differential analysis selection criteria, the database was searched for absolute changes of at least twofold in IFN- $\gamma$ treated samples relative to their untreated controls. The search was restricted to human studies and used only data derived from normal tissues or cells of any type. In total 135 of the 210 proteins that displayed changes in the protein levels in the IFN- $\gamma$ treated cells were also reported in the Interferome DB (Tables 1A, 2A). However, approximately $35 \%$ of the proteins identified in the proteomic study have not been reported to be transcriptionally responsive to IFN- $\gamma$ (Tables 1B, 2B). 
Table 1 Proteins that increased in MSC in response to IFN- $\gamma$ treatment

\begin{tabular}{|c|c|c|c|c|c|c|c|}
\hline \multirow[t]{2}{*}{ ID } & \multirow[t]{2}{*}{ Gene } & \multirow[t]{2}{*}{ Description } & \multicolumn{5}{|c|}{ Donor } \\
\hline & & & 4 & 69 & 74 & 140 & 150 \\
\hline \multicolumn{8}{|l|}{ (A) } \\
\hline Q5T3U5 & $\mathrm{ABCC} 10$ & Multidrug resistance-associated protein 7 & 1.3 & CTL & $\mathrm{CTL}$ & CTL & IFN \\
\hline Q9UPQ3 & AGAP1 & Arf-GAP with GTPase, ANK repeat and PH domain-containing protein 1 & 4.3 & 6.3 & $\mathrm{CTL}$ & 4.0 & 0.8 \\
\hline Q9ULJ7 & ANKRD50 & Ankyrin repeat domain-containing protein 50 & 1.8 & 1.0 & 5.5 & 3.8 & 3.3 \\
\hline Q6ZW76 & ANKS3 & Ankyrin repeat and SAM domain-containing protein 3 & CTL & CTL & CTL & 0.6 & CTL \\
\hline Q8NCL9 & APCDD1L & Protein APCDD1-like & CTL & 2.4 & $\mathrm{CTL}$ & 1.9 & 3.0 \\
\hline Q9BSF8 & BTBD10 & BTB/PoZ domain-containing protein 10 & CTL & CTL & CTL & CTL & CTL \\
\hline Q8N5S9 & CAMKK1 & Calcium/calmodulin-dependent protein kinase kinase 1 & CTL & CTL & 0.8 & 3.9 & CTL \\
\hline P49674 & CSNK1E & Casein kinase I isoform epsilon & 4.2 & 6.9 & 1.4 & CTL & 5.3 \\
\hline Q9Y6M4 & CSNK1G3 & Casein kinase I isoform gamma-3 & CTL & CTL & 1.1 & CTL & CTL \\
\hline P39880 & CUX1 & Homeobox protein cut-like 1 & 1.1 & CTL & CTL & 13.7 & $C T L$ \\
\hline Q9H8V3 & ECT2 & Protein ECT2 & CTL & CTL & 1.6 & 3.7 & 1.6 \\
\hline 095864 & FADS2 & Fatty acid desaturase 2 & 8.3 & 4.2 & 4.5 & 2.2 & 1.7 \\
\hline P02671 & FGA & Fibrinogen alpha chain & CTL & CTL & 73.9 & 0.5 & 4.4 \\
\hline P02679 & FGG & Fibrinogen gamma chain & 18.9 & CTL & 42.8 & 0.4 & 3.0 \\
\hline Q9NYZ3 & GTSE1 & G2 and S phase-expressed protein 1 & CTL & $\mathrm{CTL}$ & CTL & CTL & 4.0 \\
\hline Q9Y2K7 & KDM2A & Lysine-specific demethylase $2 \mathrm{~A}$ & 5.4 & 0.3 & 1.1 & CTL & 6.4 \\
\hline Q9BVG8 & KIFC3 & Kinesin-like protein KIFC3 & 5.2 & CTL & CTL & 1.5 & CTL \\
\hline Q659C4 & LARP1B & La-related protein 1B & 3.5 & CTL & CTL & CTL & CTL \\
\hline Q15013 & MAD2L1BP & MAD2L1-binding protein & CTL & CTL & CTL & 0.7 & $C T L$ \\
\hline Q07864 & POLE & DNA polymerase epsilon catalytic subunit A & CTL & CTL & 3.5 & CTL & 1.1 \\
\hline Q9P2K3 & RCOR3 & REST Corepressor 3 & CTL & CTL & CTL & CTL & CTL \\
\hline 015541 & RNF113A & RING finger protein $113 \mathrm{~A}$ & 1.2 & 1.2 & CTL & 18.5 & 4.8 \\
\hline Q9GZN7 & ROGDI & Protein rogdi homolog & CTL & 0.0 & CTL & CTL & 1.8 \\
\hline Q99719 & SEPT5 & Septin-5 & 4.8 & CTL & CTL & CTL & 0.5 \\
\hline 095359 & TACC2 & Transforming acidic coiled-coil-containing protein 2 & CTL & CTL & $\mathrm{CTL}$ & CTL & $C T L$ \\
\hline 015040 & TECPR2 & Tectonin beta-propeller repeat-containing protein 2 & 2.0 & 3.8 & CTL & 6.3 & 0.8 \\
\hline Q9P273 & TENM3 & Teneurin-3 & 3.9 & CTL & 3.2 & 2.1 & 1.3 \\
\hline Q86SZ2 & TRAPPC6B & Trafficking protein particle complex subunit 6B & 0.3 & - & CTL & CTL & CTL \\
\hline Q8IWR1 & TRIM59 & Tripartite motif-containing protein 59 & CTL & 3.2 & 4.0 & CTL & 0.9 \\
\hline Q9NPG3 & UBN1 & Ubinuclein-1 & CTL & CTL & CTL & CTL & CTL \\
\hline P62068 & USP46 & Ubiquitin carboxyl-terminal hydrolase 46 & CTL & CTL & 1.5 & CTL & CTL \\
\hline Q5ST30 & VARS2 & Valine-tRNA ligase, mitochondrial & CTL & CTL & 1.9 & 3.5 & CTL \\
\hline Q9Y2K1 & ZBTB1 & Zinc finger and BTB domain-containing protein 1 & 0.5 & CTL & $\mathrm{CTL}$ & 7.3 & $C T L$ \\
\hline Q9ULJ6 & ZMIZ1 & Zinc finger MIZ domain-containing protein 1 & 4.6 & CTL & CTL & 1.6 & CTL \\
\hline \multicolumn{8}{|l|}{ (B) } \\
\hline Q9HCE6 & ARHGEF10L & Rho guanine nucleotide exchange factor 10 -like protein & IFN & - & IFN & IFN & - \\
\hline Q61CH7 & ASPHD2 & Aspartate beta-hydroxylase domain-containing protein 2 & IFN & - & IFN & IFN & - \\
\hline Q8WXX7 & AUTS2 & Autism susceptibility gene 2 protein & IFN & - & IFN & - & IFN \\
\hline Q9BX70 & BTBD2 & BTB/POZ domain-containing protein 2 & 2.6 & 4.3 & 3.2 & IFN & - \\
\hline Q5VU97 & CACHD1 & VWFA and cache domain-containing protein 1 & 1.8 & IFN & IFN & IFN & IFN \\
\hline Q9BSQ5 & $\mathrm{CCM} 2$ & Cerebral cavernous malformations 2 protein & 2.6 & 3.9 & 3.4 & 0.5 & 3.7 \\
\hline Q86YQ8 & CPNE8 & Copine-8 & 4.4 & 5.4 & 2.0 & 3.5 & 1.9 \\
\hline Q5H9U9 & DDX60L & Probable ATP-dependentRNA helicase DDX60-like & IFN & IFN & IFN & 8.1 & 8.2 \\
\hline Q96C10 & DHX58 & Probable ATP-dependentRNA helicase DHX58 & IFN & IFN & IFN & IFN & IFN \\
\hline Q96J88 & EPSTI1 & Epithelial-stromal interaction protein 1 & IFN & IFN & IFN & IFN & IFN \\
\hline Q9BTL3 & FAM103A1 & RNMT-activating mini protein & - & - & IFN & IFN & IFN \\
\hline Q96MK3 & FAM20A & Pseudokinase FAM20A & 5.0 & 10.0 & 4.9 & IFN & IFN \\
\hline
\end{tabular}


Table 1 continued

\begin{tabular}{|c|c|c|c|c|c|c|c|}
\hline \multirow[t]{2}{*}{ ID } & \multirow[t]{2}{*}{ Gene } & \multirow[t]{2}{*}{ Description } & \multicolumn{5}{|c|}{ Donor } \\
\hline & & & 4 & 69 & 74 & 140 & 150 \\
\hline Q8IXL6 & FAM20C & Extracellular serine/threonine protein kinase FAM20C & IFN & 1.0 & IFN & 11.1 & $\mathrm{IFN}$ \\
\hline Q13480 & GAB1 & GRB2-associated-binding protein 1 & IFN & 2.2 & 4.8 & IFN & - \\
\hline Q14435 & GALNT3 & Polypeptide $\mathrm{N}$-acetylgalactosaminyltransferase 3 & IFN & 12.1 & 8.5 & 3.6 & IFN \\
\hline P36269 & GGT5 & Gamma-glutamyltransferase 5 & 6.2 & 1.0 & 16.8 & 2.5 & IFN \\
\hline Q13547 & HDAC1 & Histone deacetylase 1 & 6.8 & 1.9 & 3.6 & 4.7 & 0.8 \\
\hline P01112 & HRAS & GTPase HRas & 13.6 & 1.4 & 1.2 & 4.1 & IFN \\
\hline P01579 & IFNG & Interferon gamma & IFN & IFN & IFN & - & IFN \\
\hline Q13572 & ITPK1 & Inositol-tetrakisphosphate 1-kinase & IFN & 3.9 & 2.5 & 1.6 & 3.0 \\
\hline Q16363 & LAMA4 & Laminin subunit alpha-4 & 1.9 & 2.4 & 3.2 & 3.4 & 12.1 \\
\hline Q14392 & LRRC32 & Leucine-rich repeat-containing protein 32 & IFN & IFN & IFN & - & IFN \\
\hline P11137 & MAP2 & Microtubule-associated protein 2 & - & - & IFN & IFN & IFN \\
\hline Q96DP5 & MTFMT & Methionyl-tRNA formyltransferase, mitochondrial & - & - & IFN & IFN & IFN \\
\hline 075113 & N4BP1 & NEDD4-binding protein 1 & 3.5 & 2.0 & 2.1 & 4.6 & 3.5 \\
\hline Q7Z2Y5 & NRK & Nik-related protein kinase & - & IFN & IFN & IFN & - \\
\hline Q9Y5H3 & PCDHGA10 & Protocadherin gamma-A10 & IFN & IFN & - & IFN & - \\
\hline Q9H4M7 & PLEKHA4 & Pleckstrin homology domain-containing family A member 4 & IFN & IFN & IFN & 4.7 & IFN \\
\hline Q16647 & PTGIS & Prostacyclin synthase & IFN & 1.3 & 52.2 & 37.4 & 2.0 \\
\hline P35354 & PTGS2 & Prostaglandin G/H synthase 2 & IFN & - & - & IFN & IFN \\
\hline Q15262 & PTPRK & Receptor-type tyrosine-protein phosphatase kappa & 4.5 & 2.1 & 5.7 & 4.2 & 3.3 \\
\hline P05120 & SERPINB2 & Plasminogen activator inhibitor 2 & IFN & IFN & IFN & 1.0 & CTL \\
\hline P22732 & SLC2A5 & Solute carrier family 2, facilitated glucose transporter member 5 & IFN & IFN & - & IFN & - \\
\hline P84022 & SMAD3 & Mothers against decapentaplegic homolog 3 & 4.2 & 0.2 & 5.9 & 4.6 & 1.5 \\
\hline Q9BXI6 & TBC1D1 & TBC1 domain family member 1 & 3.8 & IFN & 10.0 & 1.5 & 2.6 \\
\hline Q9BXS4 & TMEM59 & Transmembrane protein 59 & 4.9 & IFN & IFN & 0.9 & - \\
\hline Q9BVA1 & TUBB2B & Tubulin beta-2B chain & 0.8 & 1.5 & IFN & 65.6 & IFN \\
\hline P22415 & USF1 & Upstream stimulatory factor 1 & - & - & IFN & IFN & IFN \\
\hline O75317 & USP12 & Ubiquitin carboxyl-terminal hydrolase 12 & IFN & IFN & - & 2.2 & IFN \\
\hline Q702N8 & XIRP1 & Xin actin-binding repeat-containing protein 1 & IFN & IFN & IFN & IFN & 7.3 \\
\hline Q9HCC9 & ZFYVE28 & Lateral signaling target protein 2 homolog & - & IFN & IFN & IFN & - \\
\hline
\end{tabular}

Proteins that were increased following interferon treatment with transcripts that are (A) designated as IFN- $\gamma$ responsive or (B) not designated as IFN- $\gamma$ responsive. Results are presented as fold increase following $20 \mathrm{~h}$ of IFN- $\gamma$ treatment. IFN indicates only detected in interferon treated cells. CTL indicates only detected in untreated cells. - indicates not detected in indicated donor sample

It was noteworthy that a small subset of proteins upregulated in the interferon treated group and assigned to networks by the STRING analysis (HRAS, GAB1, HDAC1, SMAD3, GGT5, PTGS2, and PTGIS) have interactions with other IFN- $\gamma$ regulated proteins. Each of these proteins was directly linked to a node in the network that was IFN- $\gamma$ responsive.

IFN- $\gamma$ induced changes in membrane and secreted proteins We were interested in the identification of IFN- $\gamma$ induced membrane associated changes as these might represent useful biomarkers to measure the response of cells to IFN- $\gamma$ treatment. The list of proteins displaying proteomic changes was analysed in Uniprot for expression of transmembrane regions [30]. A total of 47 proteins were predicted to be membrane proteins. The proteins are listed as those displaying either a gain or loss of expression in response to IFN- $\gamma$ treatment (Table 3). The proteins were enriched for the KEGG pathways "Antigen processing and presentation" (CD74, HLA-C, HLA-DPA1, HLA-DRA, HLA-E, TAP1, TAPBP; FDR $1.07 \times 10^{-8}$ ) and "Cell adhesion molecules" (CD274, HLA-C, HLA-DPA1, HLA-DRA, HLA-E, ICAM1, PDCD1LG2, VCAM1; FDR $\left.2.3 \times 10^{-8}\right)$. Although not highly significant "Arachidonic acid metabolism" (GGT5, PTGES, PTGIS; FDR 0.00472) was also over represented in the membrane proteins. There were fewer membrane proteins $(\mathrm{n}=8)$ identified that showed a decrease in expression following IFN- $\gamma$ treatment. These proteins did not appear to be associated with any clearly defined process or functions. 
Table 2 Proteins that decreased in MSC in response to IFN- $\gamma$ treatment

\begin{tabular}{|c|c|c|c|c|c|c|c|}
\hline \multirow[t]{2}{*}{ ID } & \multirow[t]{2}{*}{ Gene } & \multirow[t]{2}{*}{ Description } & \multicolumn{5}{|c|}{ Donor } \\
\hline & & & 4 & 69 & 74 & 140 & 150 \\
\hline \multicolumn{8}{|l|}{ (A) } \\
\hline Q9H6X2 & ANTXR1 & Anthrax toxin receptor 1 & 1.1 & 3.9 & CTL & 2.2 & $\mathrm{CTL}$ \\
\hline Q8IZU8 & DSEL & Dermatan-sulfate epimerase-like protein & CTL & - & CTL & - & CTL \\
\hline P17342 & NPR3 & Atrial natriuretic peptide receptor 3 & 5.2 & 1.3 & CTL & CTL & CTL \\
\hline Q14123 & PDE1C & Calcium/calmodulin-dependent $3^{\prime}, 5^{\prime}$-cyclic nucleotide phosphodiesterase $1 \mathrm{C}$ & 1.1 & 6.2 & CTL & CTL & 2.1 \\
\hline 000411 & POLRMT & DNA-directed RNA polymerase, mitochondrial & CTL & $C T L$ & 4.4 & 0.7 & 1.7 \\
\hline Q13885 & TUBB2A & Tubulin beta-2A chain & - & - & 6.5 & 11.6 & 6.4 \\
\hline Q86Y38 & $\mathrm{XYLT1}$ & Xylosyltransferase 1 & 3.0 & CTL & 3.4 & CTL & 1.3 \\
\hline \multicolumn{8}{|l|}{ (B) } \\
\hline Q9UPQ3 & AGAP1 & Arf-GAP with GTPase, ANK repeat and PH domain-containing protein 1 & 4.3 & 6.3 & CTL & 4.0 & 0.8 \\
\hline Q9ULJ7 & ANKRD50 & Ankyrin repeat domain-containing protein 50 & 1.8 & 1.0 & 5.5 & 3.8 & 3.3 \\
\hline Q6ZW76 & ANKS3 & Ankyrin repeat and SAM domain-containing protein 3 & CTL & CTL & CTL & 0.6 & CTL \\
\hline Q8NCL9 & APCDD1L & Protein APCDD1-like & CTL & 2.4 & CTL & 1.9 & 3.0 \\
\hline Q9BSF8 & BTBD10 & BTB/PoZ domain-containing protein 10 & CTL & CTL & CTL & CTL & $\mathrm{CTL}$ \\
\hline Q8N5S9 & CAMKK1 & Calcium/calmodulin-dependent protein kinase kinase 1 & CTL & $C T L$ & 0.8 & 3.9 & CTL \\
\hline P49674 & CSNK1E & Casein kinase I isoform epsilon & 4.2 & 6.9 & 1.4 & $C T L$ & 5.3 \\
\hline Q9Y6M4 & CSNK1G3 & Casein kinase I isoform gamma-3 & CTL & CTL & 1.1 & $\mathrm{CTL}$ & $\mathrm{CTL}$ \\
\hline P39880 & CUX1 & Homeobox protein cut-like 1 & 1.1 & CTL & CTL & 13.7 & $\mathrm{CTL}$ \\
\hline Q9H8V3 & ЕСT2 & Protein ECT2 & CTL & CTL & 1.6 & 3.7 & 1.6 \\
\hline O95864 & FADS2 & Fatty acid desaturase 2 & 8.3 & 4.2 & 4.5 & 2.2 & 1.7 \\
\hline P02671 & FGA & Fibrinogen alpha chain & CTL & CTL & 73.9 & 0.5 & 4.4 \\
\hline P02679 & FGG & Fibrinogen gamma chain & 18.9 & CTL & 42.8 & 0.4 & 3.0 \\
\hline Q9NYZ3 & GTSE1 & $\mathrm{G} 2$ and $\mathrm{S}$ phase-expressed protein 1 & CTL & CTL & CTL & CTL & 4.0 \\
\hline Q9Y2K7 & KDM2A & Lysine-specific demethylase 2A & 5.4 & 0.3 & 1.1 & CTL & 6.4 \\
\hline Q9BVG8 & $\mathrm{KIFC3}$ & Kinesin-like protein KIFC3 & 5.2 & $\mathrm{CTL}$ & $\mathrm{CTL}$ & 1.5 & $\mathrm{CTL}$ \\
\hline Q659C4 & LARP1B & La-related protein 1B & 3.5 & CTL & CTL & CTL & $\mathrm{CTL}$ \\
\hline Q15013 & MAD2L1BP & MAD2L1-binding protein & CTL & CTL & CTL & 0.7 & $\mathrm{CTL}$ \\
\hline Q07864 & POLE & DNA polymerase epsilon catalytic subunit A & CTL & CTL & 3.5 & CTL & 1.1 \\
\hline Q9P2K3 & RCOR3 & REST Corepressor 3 & CTL & CTL & CTL & CTL & CTL \\
\hline 015541 & RNF113A & RING finger protein $113 \mathrm{~A}$ & 1.2 & 1.2 & CTL & 18.5 & 4.8 \\
\hline Q9GZN7 & ROGDI & Protein rogdi homolog & CTL & 0.0 & CTL & $\mathrm{CTL}$ & 1.8 \\
\hline Q99719 & SEPT5 & Septin-5 & 4.8 & CTL & CTL & $\mathrm{CTL}$ & 0.5 \\
\hline O95359 & TACC2 & Transforming acidic coiled-coil-containing protein 2 & CTL & CTL & $\mathrm{CTL}$ & $\mathrm{CTL}$ & $\mathrm{CTL}$ \\
\hline 015040 & TECPR2 & Tectonin beta-propeller repeat-containing protein 2 & 2.0 & 3.8 & CTL & 6.3 & 0.8 \\
\hline Q9P273 & TENM3 & Teneurin-3 & 3.9 & CTL & 3.2 & 2.1 & 1.3 \\
\hline Q86SZ2 & TRAPPC6B & Trafficking protein particle complex subunit 6B & 0.3 & - & CTL & $\mathrm{CTL}$ & $\mathrm{CTL}$ \\
\hline Q8IWR1 & TRIM59 & Tripartite motif-containing protein 59 & CTL & 3.2 & 4.0 & $\mathrm{CTL}$ & 0.9 \\
\hline Q9NPG3 & UBN1 & Ubinuclein-1 & CTL & CTL & CTL & CTL & CTL \\
\hline P62068 & USP46 & Ubiquitin carboxyl-terminal hydrolase 46 & CTL & CTL & 1.5 & $\mathrm{CTL}$ & $\mathrm{CTL}$ \\
\hline Q5ST30 & VARS2 & Valine-tRNA ligase, mitochondrial & CTL & CTL & 1.9 & 3.5 & $\mathrm{CTL}$ \\
\hline Q9Y2K1 & ZBTB1 & Zinc finger and BTB domain-containing protein 1 & 0.5 & CTL & CTL & 7.3 & $\mathrm{CTL}$ \\
\hline Q9ULJ6 & ZMIZ1 & Zinc finger MIZ domain-containing protein 1 & 4.6 & CTL & CTL & 1.6 & $\mathrm{CTL}$ \\
\hline
\end{tabular}

Proteins that were decreased following interferon treatment with transcripts that are (A) designated as IFN- $\gamma$ responsive or (B) not designated as IFN- $\gamma$ responsive. Results are presented as fold decrease following $20 \mathrm{~h}$ of IFN- $\gamma$ treatment. IFN indicates only detected in interferon treated cells. CTL indicates only detected in untreated cells. - indicates not detected in indicated donor sample

There was also a subset of IFN- $\gamma$ responsive proteins that were predicted to lack transmembrane sequences but to contain signal peptide sequences characteristic of secreted proteins (Table 3). STRING analysis of these proteins indicated protein interaction network associated with antigen processing and presentation and fibrinolysis. 


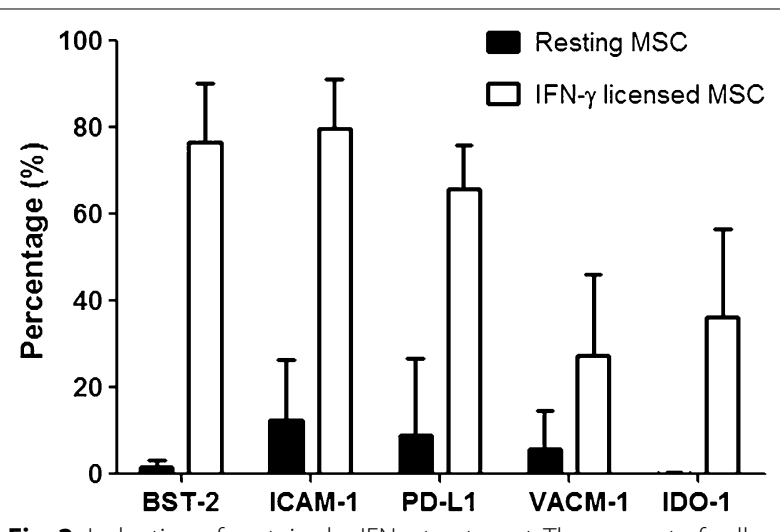

Fig. 2 Induction of proteins by IFN- $\gamma$ treatment. The percent of cells expressing the indicated proteins on untreated (resting) and IFN- $\gamma$ treated MSC were determined by flow cytometry. The data represents the mean and SD of each analysis ( $\mathrm{n}=5$ donors)

Notably fibrinogen which was downregulated following IFN- $\gamma$ treatment was part of the network (Fig. 4).

\section{Discussion}

The intent of this study was to identify IFN- $\gamma$ induced protein changes in bone marrow derived MSC as this could provide new insights regarding the immunoregulatory capacities of these cells. Additionally protein compositional changes might also offer details of the differentiation associated biochemical processes involved in MSC licensing [26]. This made it feasible to perform a compositional comparison of cell pairs from different donors using label free quantitation [31]. The results indicated that only a small subset of 210 proteins changed significantly. Approximately $2 / 3$ of these proteins displayed IFN- $\gamma$ induced directionality changes in their expression levels which were consistent with those described for their transcripts in the literature or databases. The remainder of the proteins have not been reported to be IFN- $\gamma$ responsive. These changes could be associated with either innate immune responsiveness or with the differentiation of the MSC following IFN- $\gamma$ exposure. There is also the possibility that these proteins are actually IFN- $\gamma$ responsive but their expression is post-translationally regulated. This could go undetected as the current classification of interferon responsiveness is largely based on changes in transcript levels following treatment, emphasizing the importance of proteomic analysis.

A significant proportion of the proteins that changed in response to IFN- $\gamma$ were functionally enriched in biological processes involved in host defenses, especially those associated with antiviral responses. This was to be expected given the nature of the stimulus. Such responses included alterations in antigen processing, presentation and loading (B2M, TAPs1\&2, TAPBP), foreign antigen and nucleic acid sensing (TLR3, OAS1/2/3), and ubiquitination/proteasome degradation pathways (TRIM 21, UBA7, USP18). There were also a number of other immunoregulatory proteins identified that have not previously been described in MSC cells (e.g. TAPBPL, THEMIS2, TNFAIP2).

Tapasin-related protein (TAPBPL) is a recently described regulator of peptide loading of Class I MHC complex [32-34]. This protein acts post TAP mediated loading of $\mathrm{MHC}$ to facilitate the exchange of high affinity peptides into the MHC. This provides a mechanism of assuring that $\mathrm{MHC}$ complexes remain charged with the peptide while expressed on the cell surface. This protein also provides an alternate mechanism of peptide loading of MHC I complexes, thus influencing the repertoire of peptides presented via class I molecules.

Thymocyte-selection-associated family member 2 (THEMIS2), also known as ICB1 (Induced on contact with basement membrane 1) increases the positive selection of murine B1 cells and germinal center B cells by self and foreign antigens [35]. This is achieved by lowering the threshold for B cell activation by low-avidity, but not high-avidity, antigens [36]. However, themis2 is not required for murine $B$ cell development, activation, or antibody responses [37]. THEMIS2 has also been shown to function as a signalling scaffold in the murine macrophage line, RAW 264.7, displaying pathway-specific effects on TLR responses. The over-expression of themis 2 enhanced the LPS-induced production of TNF $\alpha$, but did not impact levels of IL- 6 or Cox-2, nor TNF production induced by ligands for TLR2 or TLR3 [35].

Tumor necrosis factor alpha-induced protein 2 (TNFAIP2, also known as $\mathrm{M}-\mathrm{Sec}$ ) is A $73 \mathrm{kDa}$ cytosolic protein that can also be induced by TNF $\alpha$ [38]. TNF $\alpha$ stimulation of Hela cells over or under expressing TNFAIP2/M-Sec leads respectively to reduced or enhanced levels of IL-8 in production. There was a direct correlation between poor outcomes in septic patients and single nucleotide polymorphisms in the TNFAIP2 promoter region which enhanced protein production [39]. These observations have led to the suggestion that TNFAIP2/M-Sec is an inhibitor of NF- $\mathrm{B}$ activation. Functionally TNFAIP2/M-Sec is also essential for the formation of tunneling nanotubes (TNTs) [40]. TNTs are 50-200 $\mathrm{nm}$ diameter cellular protrusions that can connect cells up to of several cell diameters apart. These structures offer a mechanism for the transfer of small molecules as well as organelles and transport vesicles and they are of particular relevance to immune function. Dendritic cells and macrophages are among the few cell types that constitutively express TNFAIP2/M-Sec and they form TNT following antigen exposure. NK cells use 


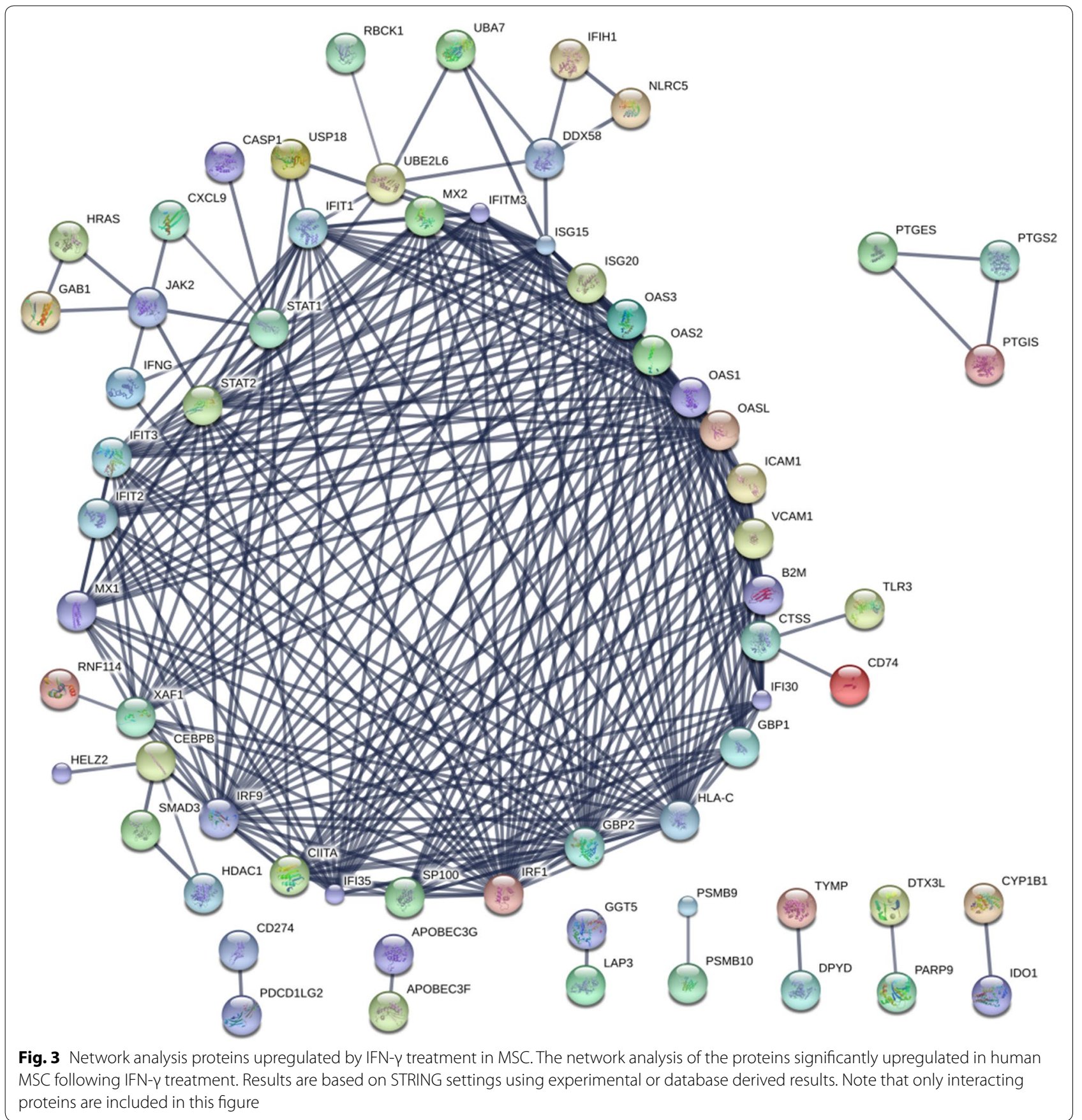

TNT as an alternate mechanism to the immune synapse for transfer of lytic granules to their targets.

The previous examples represent IFN- $\gamma$ responsive proteins that might contribute to the immunoregulatory activities of MSC. Indeed many are proposed mediators of MSC immunosuppressive activity (e.g. CD274, PDCD1LG2, ICAM1, IDO1, PTGES2) [2, 4]. However there is an additional group of proteins of potential immunological and immunoregulatory significance that are not currently described as IFN- $\gamma$ responsive (e.g. PTGS2, PTGIS, FAM20A, FAM 20C and LRRC32/ GARP).

Prostaglandin dependent mechanisms of MSC mediated immunosuppression have been described in a number of systems [41-43]. Thus it was of note that IFN- $\gamma$ treated cells produced increased levels of prostaglandin G/H synthase 2 (PTGS2/COX-2), prostacyclin synthase (PTGIS) and prostaglandin E synthase (PTGES). 
Table 3 Membrane and secreted proteins with expression levels that were differentially influenced by IFN- $\gamma$ treatment

\begin{tabular}{|c|c|c|c|c|}
\hline Entry & Gene & TM & SP & $\mathbf{R I}^{*}$ \\
\hline Q9H6X2 & ANTXR1 & + & + & $\mathrm{D}$ \\
\hline Q8NCL9 & APCDD1L & + & + & $\mathrm{D}$ \\
\hline 000478 & BTN3A3 & + & + & I \\
\hline Q5VU97 & CACHD1 & + & + & 1 \\
\hline Q9NZQ7 & CD274 & + & + & I \\
\hline Q8IZU8 & DSEL & + & + & $\mathrm{D}$ \\
\hline P30504 & HLA-C & + & + & 1 \\
\hline P20036 & HLA-DPA1 & + & + & I \\
\hline P01903 & HLA-DRA & + & + & 1 \\
\hline P13747 & HLA-E & + & + & I \\
\hline P30511 & $\mathrm{HLA}-\mathrm{F}$ & + & + & I \\
\hline P05362 & ICAM1 & + & + & I \\
\hline Q14392 & LRRC32 & + & + & I \\
\hline P17342 & NPR3 & + & + & $\mathrm{D}$ \\
\hline Q9Y5H3 & PCDHGA10 & + & + & I \\
\hline Q9BQ51 & PDCD1LG2 & + & + & I \\
\hline Q15262 & PTPRK & + & + & I \\
\hline Q8WVN6 & SECTM1 & + & + & I \\
\hline 015533 & TAPBP & + & + & I \\
\hline Q9BX59 & TAPBPL & + & + & I \\
\hline 015455 & TLR3 & + & + & 1 \\
\hline Q9BXS4 & TMEM59 & + & + & 1 \\
\hline P19320 & VCAM1 & + & + & I \\
\hline Q5T3U5 & $\mathrm{ABCC} 10$ & + & & $D$ \\
\hline Q9ULC5 & ACSL5 & + & & 1 \\
\hline Q6ICH7 & ASPHD2 & + & & 1 \\
\hline 075110 & ATP9A & + & & I \\
\hline 043286 & B4GALT5 & + & & I \\
\hline Q10589 & BST2 & + & & 1 \\
\hline P04233 & CD74 & + & & 1 \\
\hline 015247 & CLIC2 & + & & I \\
\hline O95864 & FADS2 & + & & $\mathrm{D}$ \\
\hline Q14435 & GALNT3 & + & & । \\
\hline P36269 & GGT5 & + & & 1 \\
\hline Q01628 & IFITM3 & + & & 1 \\
\hline 015162 & PLSCR1 & + & & I \\
\hline 014684 & PTGES & + & & 1 \\
\hline Q16647 & PTGIS & + & & 1 \\
\hline Q9Y666 & SLC12A7 & + & & 1 \\
\hline P22732 & SLC2A5 & + & & I \\
\hline Q03518 & TAP1 & + & & I \\
\hline Q03519 & TAP2 & + & & I \\
\hline Q9P273 & TENM3 & + & & $D$ \\
\hline Q8IWR1 & TRIM59 & + & & I \\
\hline O95183 & VAMP5 & + & & I \\
\hline Q86Y07 & VRK2 & + & & I \\
\hline Q86Y38 & XYLT1 & + & & $\mathrm{D}$ \\
\hline 014791 & APOL1 & & + & I \\
\hline
\end{tabular}

Table 3 continued

\begin{tabular}{|c|c|c|c|c|}
\hline Entry & Gene & TM & SP & $\mathbf{R I}^{*}$ \\
\hline P61769 & B2 M & & + & I \\
\hline P09871 & C1S & & + & I \\
\hline P08603 & $\mathrm{CFH}$ & & + & 1 \\
\hline P25774 & CTSS & & + & I \\
\hline Q07325 & CXCL9 & & + & 1 \\
\hline Q96MK3 & FAM20A & & + & I \\
\hline Q8IXL6 & FAM20C & & + & 1 \\
\hline P02671 & FGA & & + & $\mathrm{D}$ \\
\hline P02679 & FGG & & + & $\mathrm{D}$ \\
\hline P13284 & IFI30 & & + & I \\
\hline P01579 & IFNG & & + & 1 \\
\hline Q16363 & LAMA4 & & + & 1 \\
\hline Q08380 & LGALS3BP & & + & I \\
\hline P35354 & PTGS2 & & + & 1 \\
\hline P05120 & SERPINB2 & & + & I \\
\hline P05155 & SERPING1 & & + & I \\
\hline
\end{tabular}

*Proteins with transmembrane regions (TM) or signal peptides (SP) that were significantly changed in Response to IFN- $\gamma$ treatment (RI) are indicated as either increased (I) or decreased (D) in the column labelled RI

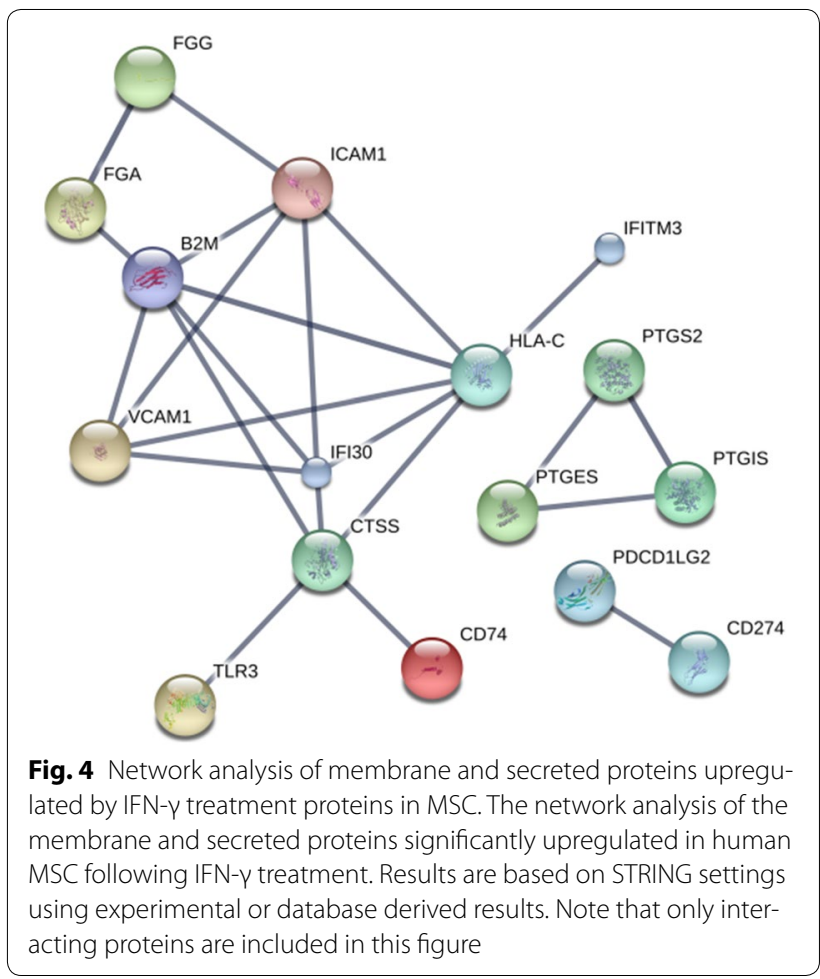

This could provide a mechanism for increased production of prostaglandin $\mathrm{H}_{2}$ and downstream prostenoids. Although the inhibitory activity of $\mathrm{PGE}_{2}$ has been well documented prostacyclin has also been shown to have potent immunoregulatory properties. Prostacyclin synthase which generates prostacyclin is expressed by follicular dendritic cells in germinal centres of lymphoid 
organs [44]. PTGIS inhibits $\mathrm{T}$ cell activation while delaying the onset of apoptosis in these cells. Follicular dendritic-like HK cells have been shown to enhance the antigen presenting capacity of B cells, in part by induction of CD86 on the B cell surface. This effect is also observed with prostacyclin [3]. PTGIS contains an IFN- $\gamma$ response element in $5^{\prime}$ region upstream of the translational initiation site [45]. However responsiveness to IFN- $\gamma$ has not previously been reported.

The FAM20A and FAM20C are members of a family of secreted proteins [46]. FAM20A is differentially expressed in developing hematopoietic cells and it has recently been shown to be required for the appropriate compartmental distribution of and secretion of FAM20C [47]. FAM20C is an extracellular kinase that recognizes a consensus $\mathrm{S}-\mathrm{x}-\mathrm{E} / \mathrm{S}$ sequence as a phosphorylation target. The broad specificity of the enzyme suggests that it may account for a large proportion of all extracellular phosphoproteins observed in humans [48]. Functionally the proteins targeted for phosphorylation are enriched in GO processes associated with adhesion, migration, invasion and wound healing. These observations have led to suggestions that FAM20C expression may contribute to the regulation of immune cell function and activity following IFN- $\gamma$ treatment.

Epithelial stromal interaction protein 1 (EPSTI1) is a $37 \mathrm{kDa}$ protein that was first identified in human breast cancer cells [49]. It has recently been shown to possess anti-apoptotic activity in human breast cancer cells [50]. The molecule is broadly expressed with highest message levels in the small intestine, spleen, salivary glands, and testes. EPSTI1 is an interferon response gene that is inducible by Type I interferon and the $\lambda$ interferon (IL28A) [51]. However, there have not been reports of IFN- $\gamma$ responsiveness.

Leucine rich repeats containing 32/glycoprotein A repetitions predominant (LRRC32/GARP) is a type I membrane protein that binds and presents latent TGF- $\beta$ in an active state on the surface of platelets, Tregs and MSC [52-54]. The protein has been demonstrated on the surface of human and murine MSC [55]. Our studies extend this by demonstrating that IFN- $\gamma$ treatment enhanced production of LRRC32/GARP in human MSC. Although LRRC32/GARP message levels are only modestly upregulated by IFN- $\gamma$ in other cell types, a recent publication demonstrated that protein levels were markedly increased murine macrophages following IFN- $\gamma$ treatment.

The present studies demonstrate the value of direct measurements of protein expression patterns as many of the observed changes would apparently not have been predicted based on transcriptome analysis in other cell types. However, independent of these correlations it appears that there are a large number of immunoregulatory molecules that are altered following IFN- $\gamma$ treatments and these may provide additional insights regarding the immunosuppressive mechanisms employed by licensed MSC. The identification of a significant number of membrane proteins that were differentially regulated following interferon treatment raises the possibility that these may represent potentially novel candidates for monitoring stem cell responsiveness to IFN- $\gamma$. While it remains to be determined which, if any, of these proteins actually correlates with the immunoregulatory activities of the IFN- $\gamma$ treated MSC, the current results do indicate that are a large number of yet unassessed candidates. Additionally the present study offers one of the most in depth analysis of the basal and IFN- $\gamma$ induced proteomes of bone marrow derived human MSC to date. This information may provide a baseline for the comparative analysis of the responses of these cells to other licensing agents.

\section{Additional file}

Additional file 1: Table S1. Summary data of identifications, intensities and normalised $z$ scores of differences (i.e. of $[D=$ (IFN intensity)-(CTL intensity)]. CTL and IFN refer respectively to cumulative peak intensities of peptides $(\log 2)$ for a given protein in untreated and interferon treated pairs of cells from the same donor. $Z$ corresponds to the normalised z score for the differences observed for each protein (i.e. of [D $=$ (IFN intensity)-(CTL intensity)] relative to the mean of the distribution within their corresponding donor pair.

\section{Authors' contributions}

QG and DW, OK, JW designed the experiments; QG respectively designed and performed the culture and FACS analysis. PE designed and performed the MS analysis. VS and JW analyzed the data. JW wrote the manuscript. All authors read and approved the final manuscript.

\section{Author details}

${ }^{1}$ Manitoba Centre for Advanced Cell and Tissue Therapy, Department of Pediatrics and Child Health, University of Manitoba, Winnipeg, MB, Canada. ${ }^{2}$ Cellular Therapy Laboratory, CancerCare Manitoba, Winnipeg, MB, Canada. ${ }^{3}$ Manitoba Centre for Proteomics and Systems Biology, Section of Biomedical Proteomics, Department of Internal Medicine, Rady Faculty of Health Sciences, University of Manitoba and Health Sciences Centre, 799 John Buhler Research Centre, 715 McDermot Ave, Winnipeg, MB R3E 3P4, Canada. ${ }^{4}$ Division of Haematology/Oncology, Department of Paediatrics, The Hospital for Sick Children, University of Toronto, Toronto, ON, Canada.

\section{Competing interests}

The authors declare that they have no competing interests.

\section{Availability of data and materials}

Spectra (in MGF format) and protein quantitation results are available at the University of California, San Diego's MassIVE archive (massive.ucsd.edu) under the Accession MSV000080890.

\section{Ethics approval and consent to participate}

This study was approved by University of Manitoba Health Research Ethics Board (Ethics Number H2012:061). All materials were obtained with informed consent. 


\section{Funding}

This study was supported by The Bihlers'Professorship in Stem Cell Research (D.A.W.), Stem Cell Network Impact Grant (Grant Number 13/5226, D.A.W. and Q.G.), and MS Society of Canada Fellowship Award and Mindel \& Tom Olenick Research Award in Immunology (Q.G.)

\section{Publisher's Note}

Springer Nature remains neutral with regard to jurisdictional claims in published maps and institutional affiliations.

\section{Received: 11 April 2017 Accepted: 28 June 2017}

Published online: 06 July 2017

\section{References}

1. Wang Y, Chen F, Gu B, Chen G, Chang H, Wu D. Mesenchymal stromal cells as an adjuvant treatment for severe late-onset hemorrhagic cystitis after allogeneic hematopoietic stem cell transplantation. Acta Haematol. 2015;133(1):72-7.

2. Dazzi F, Krampera M. Mesenchymal stem cells and autoimmune diseases. Best Pract Res Clin Haematol. 2011;24(1):49-57.

3. Kim J, Kim YM, Jeoung DI, Choe J. Human follicular dendritic cells promote the APC capability of B cells by enhancing CD86 expression levels. Cell Immunol. 2012;273(2):109-14.

4. Mariani E, Facchini A. Clinical applications and biosafety of human adult mesenchymal stem cells. Curr Pharm Des. 2012;18(13):1821-45.

5. Chinnadurai R, Copland IB, Patel SR, Galipeau J. IDO-independent suppression of T cell effector function by IFN-gamma-licensed human mesenchymal stromal cells. J Immunol. 2014;192(4):1491-501.

6. Francois M, Romieu-Mourez R, Li M, Galipeau J. Human MSC suppression correlates with cytokine induction of indoleamine 2,3-dioxygenase and bystander $\mathrm{M} 2$ macrophage differentiation. Mol Ther. 2012;20(1):187-95.

7. Curti A, Trabanelli S, Salvestrini V, Baccarani M, Lemoli RM. The role of indoleamine 2,3-dioxygenase in the induction of immune tolerance: focus on hematology. Blood. 2009;113(11):2394-401.

8. Shi Y, Hu G, Su J, Li W, Chen Q, Shou P, Xu C, Chen X, Huang Y, Zhu Z, et al. Mesenchymal stem cells: a new strategy for immunosuppression and tissue repair. Cell Res. 2010;20(5):510-8.

9. Duffy MM, Ritter T, Ceredig R, Griffin MD. Mesenchymal stem cell effects on T-cell effector pathways. Stem Cell Res Ther. 2011;2(4):34.

10. Liu YL, Wang YD, Zhuang F, Xian SL, Fang JY, Su W, Zhang W. Immunosuppression effects of bone marrow mesenchymal stem cells on renal interstitial injury in rats with unilateral ureteral obstruction. Cell Immunol. 2012;276(1-2):144-52.

11. Stagg J, Galipeau J. Mechanisms of immune modulation by mesenchymal stromal cells and clinical translation. Curr Mol Med. 2013;13(5):856-67.

12. Chinnadurai R, Copland IB, Garcia MA, Petersen CT, Lewis CN, Waller EK, Kirk AD, Galipeau J. Cryopreserved mesenchymal stromal cells are susceptible to T-cell mediated apoptosis which is partly rescued by IFNgamma licensing. Stem Cells. 2016;34(9):2429-42.

13. Krampera M, Galipeau J, Shi Y, Tarte K, Sensebe L. Therapy MSCCotISfC: immunological characterization of multipotent mesenchymal stroma cells-The International Society for Cellular Therapy (ISCT) working proposal. Cytotherapy. 2013;15(9):1054-61.

14. Sivanathan KN, Rojas-Canales DM, Hope CM, Krishnan R, Carroll RP, Gronthos S, Grey ST, Coates PT. Interleukin-17A-induced human mesenchymal stem cells are superior modulators of immunological function. Stem Cells. 2015;33(9):2850-63.

15. Waterman RS, Tomchuck SL, Henkle SL, Betancourt AM. A new mesenchymal stem cell (MSC) paradigm: polarization into a pro-inflammatory MSC1 or an Immunosuppressive MSC2 phenotype. PLoS ONE. 2010;5(4):e10088.

16. Billing AM, Ben Hamidane H, Dib SS, Cotton RJ, Bhagwat AM, Kumar P, Hayat S, Yousri NA, Goswami N, Suhre K, et al. Comprehensive transcriptomic and proteomic characterization of human mesenchymal stem cells reveals source specific cellular markers. Sci Rep. 2016;6:21507.
17. Jeon OH, Panicker LM, Lu Q, Chae JJ, Feldman RA, Elisseeff JH. Human iPSC-derived osteoblasts and osteoclasts together promote bone regeneration in 3D biomaterials. Sci Rep. 2016;6:26761.

18. Anjo SI, Lourenco AS, Melo MN, Santa C, Manadas B. Unraveling mesenchymal stem cells' dynamic secretome through nontargeted proteomics profiling. Methods Mol Biol. 2016;1416:521-49.

19. Assoni A, Coatti G, Valadares MC, Beccari M, Gomes J, Pelatti M, MitneNeto M, Carvalho VM, Zatz M. different donors mesenchymal stromal cells secretomes reveal heterogeneous profile of relevance for therapeutic use. Stem Cells Dev. 2017;26(3):206-14.

20. Lavoie JR, Rosu-Myles M. Uncovering the secretes of mesenchymal stem cells. Biochimie. 2013;95(12):2212-21.

21. Hanley PJ, Mei Z, da Graca Cabreira-Hansen M, Klis M, Li W, Zhao Y, Durett AG, Zheng X, Wang Y, Gee AP, et al. Manufacturing mesenchymal stromal cells for phase I clinical trials. Cytotherapy. 2013;15(4):416-22.

22. Romieu-Mourez R, Francois M, Boivin MN, Stagg J, Galipeau J. Regulation of $\mathrm{MHC}$ class $\|$ expression and antigen processing in murine and human mesenchymal stromal cells by IFN-gamma, TGF-beta, and cell density. J Immunol. 2007;179(3):1549-58.

23. Dominici M, Le Blanc K, Mueller I, Slaper-Cortenbach I, Marini F, Krause D, Deans R, Keating A, Prockop D, Horwitz E. Minimal criteria for defining multipotent mesenchymal stromal cells. The International Society for Cellular Therapy position statement. Cytotherapy. 2006;8(4):315-7.

24. Trojahn Kolle SF, Oliveri RS, Glovinski PV, Kirchhoff M, Mathiasen AB, Elberg JJ, Andersen PS, Drzewiecki KT, Fischer-Nielsen A. Pooled human platelet lysate versus fetal bovine serum-investigating the proliferation rate, chromosome stability and angiogenic potential of human adipose tissue-derived stem cells intended for clinical use. Cytotherapy. 2013;15(9):1086-97.

25. Wisniewski JR, Zougman A, Nagaraj N, Mann M. Universal sample preparation method for proteome analysis. Nat Methods. 2009;6(5):359-62.

26. Dwivedi RC, Spicer V, Harder M, Antonovici M, Ens W, Standing KG, Wilkins JA, Krokhin OV. Practical implementation of 2D HPLC scheme with accurate peptide retention prediction in both dimensions for highthroughput bottom-up proteomics. Anal Chem. 2008;80(18):7036-42.

27. Bowden P, Beavis R, Marshall J. Tandem mass spectrometry of human tryptic blood peptides calculated by a statistical algorithm and captured by a relational database with exploration by a general statistical analysis system. J Proteomics. 2009;73(1):103-11.

28. Szklarczyk D, Morris JH, Cook H, Kuhn M, Wyder S, Simonovic M, Santos A, Doncheva NT, Roth A, Bork P, et al. The STRING database in 2017: quality-controlled protein-protein association networks, made broadly accessible. Nucleic Acids Res. 2017;45(D1):D362-8.

29. Rusinova I, Forster S, Yu S, Kannan A, Masse M, Cumming H, Chapman R, Hertzog PJ. Interferome v2.0: an updated database of annotated interferon-regulated genes. Nucleic Acids Res. 2013;41(Database issue):D1040-6.

30. The UniProt C. UniProt: the universal protein knowledgebase. Nucleic Acids Res. 2017:45(D1):D158-69.

31. McQueen P, Spicer V, Schellenberg J, Krokhin O, Sparling R, Levin D, Wilkins JA. Whole cell, label free protein quantitation with data independent acquisition: quantitation at the MS2 level. Proteomics. 2015;15(1):16-24.

32. Boyle LH, Hermann C, Boname JM, Porter KM, Patel PA, Burr ML, Duncan LM, Harbour ME, Rhodes DA, Skjodt K, et al. Tapasin-related protein TAPBPR is an additional component of the MHC class I presentation pathway. Proc Natl Acad Sci USA. 2013;110(9):3465-70.

33. Hermann C, Trowsdale J, Boyle LH. TAPBPR: a new player in the MHC class I presentation pathway. Tissue Antigens. 2015;85(3):155-66.

34. Hermann C, van Hateren A, Trautwein N, Neerincx A, Duriez PJ, Stevanovic S, Trowsdale J, Deane JE, Elliott T, Boyle LH. TAPBPR alters MHC class I peptide presentation by functioning as a peptide exchange catalyst. Elife. 2015;4:e09617.

35. Peirce MJ, Brook M, Morrice N, Snelgrove R, Begum S, Lanfrancotti A, Notley C, Hussell T, Cope AP, Wait R. Themis2/ICB1 is a signaling scaffold that selectively regulates macrophage Toll-like receptor signaling and cytokine production. PLOS ONE. 2010;5(7):e11465.

36. Cheng D, Deobagkar-Lele M, Zvezdova E, Choi S, Uehara S, Baup D, Bennett SC, Bull KR, Crockford TL, Ferry H, et al. Themis2 lowers the threshold for $B$ cell activation during positive selection. Nat Immunol. 2017;18(2):205-13. 
37. Hartweger H, Schweighoffer E, Davidson S, Peirce MJ, Wack A, Tybulewicz $\mathrm{VL}$. Themis 2 is not required for $\mathrm{B}$ cell development, activation, and antibody responses. J Immunol. 2014;193(2):700-7.

38. Wolf FW, Sarma V, Seldin M, Drake S, Suchard SJ, Shao H, O'Shea KS, Dixit VM. B94, a primary response gene inducible by tumor necrosis factoralpha, is expressed in developing hematopoietic tissues and the sperm acrosome. J Biol Chem. 1994;269(5):3633-40

39. Thair SA, Topchiy E, Boyd JH, Cirstea M, Wang C, Nakada TA, Fjell CD, Wurfel M, Russell JA, Walley KR. TNFAIP2 inhibits early TNFalpha-induced NF-x03BA;B signaling and decreases survival in septic shock patients. J Innate Immun. 2016;8(1):57-66.

40. Kimura S, Hase K, Ohno H. Tunneling nanotubes: emerging view of their molecular components and formation mechanisms. Exp Cell Res. 2012;318(14):1699-706.

41. Duffy MM, Pindjakova J, Hanley SA, McCarthy C, Weidhofer GA, Sweeney EM, English K, Shaw G, Murphy JM, Barry FP, et al. Mesenchymal stem cell inhibition of T-helper 17 cell- differentiation is triggered by cell-cell contact and mediated by prostaglandin E2 via the EP4 receptor. Eur J Immunol. 2011;41(10):2840-51.

42. Noone C, Kihm A, English K, O'Dea S, Mahon BP. IFN-gamma stimulated human umbilical-tissue-derived cells potently suppress NK activation and resist NK-mediated cytotoxicity in vitro. Stem Cells Dev. 2013;22(22):3003-14.

43. Szabo E, Fajka-Boja R, Kriston-Pal E, Hornung A, Makra I, Kudlik G, Uher F, Katona RL, Monostori E, Czibula A. Licensing by inflammatory cytokines abolishes heterogeneity of immunosuppressive function of mesenchymal stem cell population. Stem Cells Dev. 2015;24(18):2171-80.

44. Lee IY, Ko EM, Kim SH, Jeoung DI, Choe J. Human follicular dendritic cells express prostacyclin synthase: a novel mechanism to control T cell numbers in the germinal center. J Immunol. 2005;175(3):1658-64.

45. Yokoyama C, Yabuki T, Inoue H, Tone Y, Hara S, Hatae T, Nagata M, Takahashi El, Tanabe T. Human gene encoding prostacyclin synthase (PTGIS): genomic organization, chromosomal localization, and promoter activity. Genomics. 1996;36(2):296-304.
46. Nalbant D, Youn H, Nalbant SI, Sharma S, Cobos E, Beale EG, Du Y, Williams SC. FAM20: an evolutionarily conserved family of secreted proteins expressed in hematopoietic cells. BMC Genom. 2005;6:11.

47. Ohyama Y, Lin JH, Govitvattana N, Lin IP, Venkitapathi S, Alamoudi A, Husein D, An C, Hotta H, Kaku M, et al. FAM20A binds to and regulates FAM20C localization. Sci Rep. 2016;6:27784.

48. Tagliabracci VS, Wiley SE, Guo X, Kinch LN, Durrant E, Wen J, Xiao J, Cui J, Nguyen KB, Engel JL, et al. A single kinase generates the majority of the secreted phosphoproteome. Cell. 2015;161(7):1619-32.

49. Nielsen HL, Ronnov-Jessen L, Villadsen R, Petersen OW. Identification of EPSTI1, a novel gene induced by epithelial-stromal interaction in human breast cancer. Genomics. 2002;79(5):703-10.

50. Capdevila-Busquets E, Badiola N, Arroyo R, Alcalde V, Soler-Lopez M, Aloy P. Breast cancer genes PSMC3IP and EPSTI1 play a role in apoptosis regulation. PLOS ONE. 2015;10(1):e0115352.

51. Meng X, Yang D, Yu R, Zhu H. EPSTI1 is involved in IL-28A-mediated inhibition of HCV infection. Mediators Inflamm. 2015;2015:716315.

52. Andersson J, Tran DQ, Pesu M, Davidson TS, Ramsey H, O'Shea JJ, Shevach EM. CD4+ FoxP3 + regulatory T cells confer infectious tolerance in a TGF-beta-dependent manner. J Exp Med. 2008;205(9):1975-81.

53. Edwards JP, Hand TW, Morais da Fonseca D, Glass DD, Belkaid Y, Shevach EM. The GARP/Latent TGF-beta1 complex on Treg cells modulates the induction of peripherally derived Treg cells during oral tolerance. Eur J Immunol. 2016;46(6):1480-9.

54. Fridrich S, Hahn SA, Linzmaier M, Felten M, Zwarg J, Lennerz V, Tuettenberg A, Stocker W. How soluble GARP enhances TGFbeta activation. PLoS ONE. 2016;11(4):e0153290.

55. Carrillo-Galvez AB, Cobo M, Cuevas-Ocana S, Gutierrez-Guerrero A, Sanchez-Gilabert A, Bongarzone P, Garcia-Perez A, Munoz P, Benabdellah $\mathrm{K}$, Toscano MG, et al. Mesenchymal stromal cells express GARP/LRRC32 on their surface: effects on their biology and immunomodulatory capacity. Stem Cells. 2015;33(1):183-95.

\section{Submit your next manuscript to BioMed Central and we will help you at every step:}

- We accept pre-submission inquiries

- Our selector tool helps you to find the most relevant journal

- We provide round the clock customer support

- Convenient online submission

- Thorough peer review

- Inclusion in PubMed and all major indexing services

- Maximum visibility for your research

Submit your manuscript at www.biomedcentral.com/submit
() Biomed Central 